\title{
In vivo antioxidant activities of Curcuma longa and Curcuma xanthorrhiza: a
} review

\author{
${ }^{1}$ Lukitaningsih, E., ${ }^{1,2^{*}}$ Rohman, A., ${ }^{3}$ Rafi, M., ${ }^{4}$ Nurrulhidayah, A.F. and ${ }^{5}$ Windarsih, A. \\ ${ }^{I}$ Department of Pharmaceutical Chemistry, Faculty of Pharmacy, Universitas Gadjah Mada, Yogyakarta \\ 55281, Indonesia \\ ${ }^{2}$ Institute of Halal Industry and Systems, Universitas Gadjah Mada, Yogyakarta 55281, Indonesia \\ ${ }^{3}$ Department of Chemistry, Faculty of Mathematics and Natural Sciences, IPB University, Jalan Tanjung \\ Kampus IPB Dramaga, Bogor 16680, Indonesia. \\ ${ }^{4}$ International Institute for Halal Research and Training (INHART), International Islamic University \\ Malaysia, Gombak, 50728, Kuala Lumpur, Malaysia. \\ ${ }^{5}$ Research Unit for Natural Products Technology (BPTBA), Indonesian Institute of Sciences (LIPI), \\ Yogyakarta 55861, Indonesia
}

\section{Article history: \\ Received: 29 March 2019 \\ Received in revised form: 31 \\ May 2019 \\ Accepted: 4 June 2019 \\ Available Online: 9 June \\ 2019}

Keywords:

Curcuma longa,

Curcuma xanthorrhiza,

Natural antioxidant,

In vivo,

Antioxidant enzymes

DOI:

https://doi.org/10.26656/fr.2017.4(1).172

\begin{abstract}
Free radicals, reactive nitrogen species (RNS) and reactive oxygen species (ROS) have been known to contribute several degenerative diseases such as cardiovascular diseases, cancers, rheumatoid arthritis, neurodegenerative, and diabetes mellitus. In order to overcome the negative effects of these radicals, some scientist explores natural antioxidants from plants. Curcuma longa (Turmeric) and Curcuma xanthorrhiza (Javanese Turmeric) have been known as herbs and spices with antioxidant activities due to curcuminoid contained. Antioxidant can be defined as any substances or samples capable of inhibiting free radical reactions in the oxidation reaction. Several chemical and biological methods either in vitro or in vivo have been proposed, evaluated, and used for antioxidant evaluation of studied samples. Antioxidant activities in vivo can be measured by determining antioxidant enzymes which include catalase, glutathione reductase, superoxide dismutase, glutathione peroxidase, and glutathione S-transferase. The antioxidant enzymes increased while the lipid peroxidation decreased for both Curcuma species when research using animal models. This present review highlights the potential use of C. longa and C. xanthorrhiza as natural antioxidants in vivo. Based on in vivo studies, Curcuma species are potential sources of natural antioxidants, which can be used as food supplements.
\end{abstract}

\section{Introduction}

Herbs and spices are traditionally defined as any part of plants used in the diet for their aromatic properties with no or low nutritional values (Serafini and Peluso, 2016). Currently, herbs and spices are largely used for health-promoting purposes due to the antioxidant properties of the phytochemicals contained in these plants (Dragland et al., 2003). Therefore, herbs and spices such as Curcuma longa and Curcuma xanthorrhiza may have a role in antioxidant defense and redox signaling, and there are large numbers of literature reporting the potential benefits of these herbs and spices from the health perspectives (Tapsell et al., 2006; Hosseini and Hosseinzadeh, 2018). As a consequence, natural antioxidants coming from herbs and spices are extensively explored as an alternative to synthetic antioxidants for safety reasons (Opara and Chohan, 2014).

Natural antioxidants can be defined as the phytochemicals capable of counteracting the damaging effects of the oxidative physiological processes which occur in the tissues (Podsedek, 2007). The antioxidants are believed to play important role in preventing the oxidative stress-related diseases such as cancer, heart disease, diabetes, stroke, rheumatoid arthritis, Alzheimer's disease, aging and cataracts (Kumar et al., 2017). Natural antioxidants are typically derived from plant sources, and its efficacy is depended on several factors, namely plant species and its variety, extraction methods, and the growing conditions. Polyphenols such as phenolic acids, the flavonoids including flavonols, flavones, isoflavones, flavanones, flavanols and the 
anthocyanidins, the stilbenes and the lignans are believed as phytochemicals contributing to act as natural antioxidants in plants (Pandey and Risvi, 2009; Jiang, 2019). The action mode for these phytochemicals as natural antioxidants will vary depending upon the source of plant materials, the presence of synergists and antagonists, and of course the matrix in which the natural antioxidants were applied (Harwort, 2003).

Curcuma, the group of family Zingiberaceae, is an economically important genus due to its use in medicinal and food sectors (Xia et al., 2005). Curcuma genus has been reported to comprise 70 perennial rhizomatous species, widely distributed along tropical and subtropical regions around the world. The rhizomes of Curcuma species is a source of the yellow dye and historically has been exploited as spices and food preservatives, flavoring agent, and remedy for the treatment of many diseases due to chemical compounds contained (Rajkumari et al., 2017). The main components which are believed to be responsible for several biological activities of Curcuma species including antioxidants are curcuminoid (Nugroho et al., 2015), a group of phenolics compounds of curcumin, demethoxycurcumin and bisdemethoxycurcumin (Figure 1). In this review, the antioxidant activities in vivo of $C$. longa and C. xanthorrhiza were highlighted.
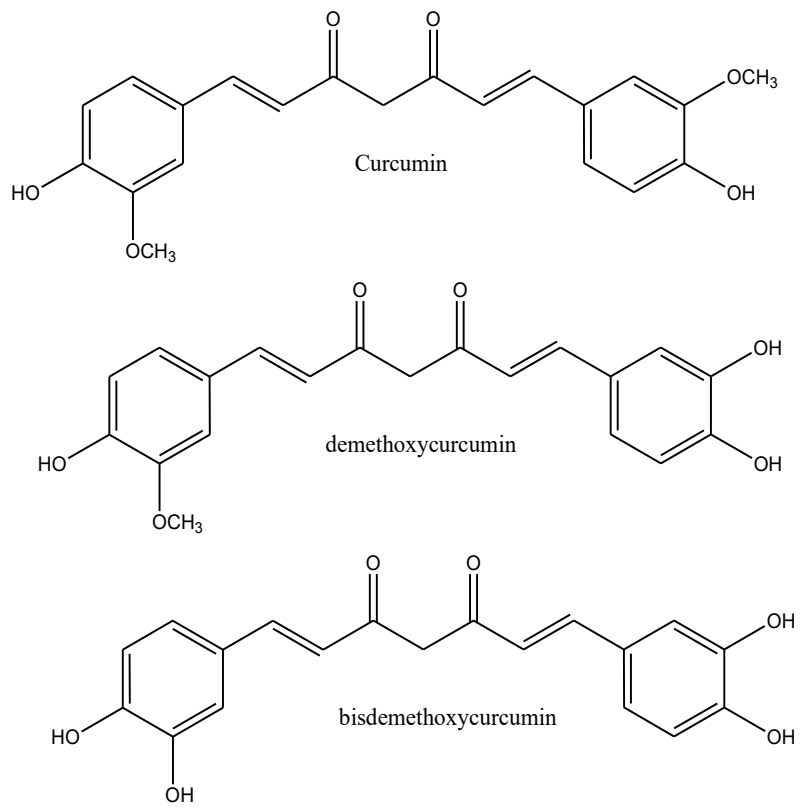

Figure 1. The chemical structures of curcumin, demethoxycurcumin and bisdemethoxycurcumin (Nugroho et al., 2015) in Curcuma species and xanthorrhizol in Curcuma xanthorrhiza (Ramdani et al., 2016).

\section{Methods}

Several databases including Scopus, PubMed, and Google Scholar were used for preparing this review. These databases were identified, analyzed and selected to obtain the most appropriate ones. The keywords used during searching of information was (antioxidant + Curcuma longa + in vivo) or (antioxidant + Curcuma xanthorrhiza + in vivo) in the month of May-June 2018.

\section{Evaluation of in vivo antioxidant activities}

Evaluation of antioxidant in vivo typically was performed using animal models in which the animals were administrated with tested samples at certain doses along with positive controls such as tocopherols and phenolic compounds (Moniruzzaman et al., 2012). After a specified time of treatment period, the animals were sacrificed and the tissue or blood was exploited for in vivo antioxidant assay, and antioxidant enzymes were measured. Several enzymes namely catalase, glutathione reductase, superoxide dismutase, glutathione peroxidase, gamma-glutamyl transpeptidase activity, and glutathione S-transferase were measured. Besides, glutathione levels and lipid peroxidation were also used as indicative of antioxidant activity in vivo (Nur Alam et al., 2013).

Catalase (CAT) enzyme converts hydrogen peroxide $\left(\mathrm{H}_{2} \mathrm{O}_{2}\right)$ to water and oxygen. This enzyme activity is largely located in peroxisomes, subcellular organelles (Weydert et al., 2010). The activity of CAT is usually determined by involving the incubation of a test tube containing $0.5 \mathrm{~mL}$ of $\mathrm{H}_{2} \mathrm{O}_{2}$ and $0.1 \mathrm{~mL}$ of pancreatic homogenate in a water bath at temperature of $37^{\circ} \mathrm{C}$ for 1 minute. After incubation, the reaction is terminated using $0.5 \mathrm{~mL}$ of ammonium molybdate solution. A yellow color due to complex of ammonium molybdate and $\mathrm{H}_{2} \mathrm{O}_{2}$ is formed. The absorbance is measured at wavelength $405 \mathrm{~nm}$ using a spectrophotometer. One unit of catalase is usually defined as the amount of CAT enzyme capable of catalyzing the decomposition of $1 \mu \mathrm{mol}$ of $\mathrm{H}_{2} \mathrm{O}_{2}$ per min (Lubrano and Balzan, 2015).

Superoxide dismutase (SOD) is an enzyme which catalyzes the partitioning or dismutation the superoxide radicals $\left(\mathrm{O}_{2}^{-}\right)$into either hydrogen peroxide $\left(\mathrm{H}_{2} \mathrm{O}_{2}\right)$ or molecular oxygen $\left(\mathrm{O}_{2}\right) \cdot \mathrm{H}_{2} \mathrm{O}_{2}$ is also damaging cells because it is easily converted into hydroxyl radical, therefore, $\mathrm{H}_{2} \mathrm{O}_{2}$ is degraded by catalase. Therefore, $\mathrm{SOD}$ and catalase are considered as an important antioxidant defense in nearly all living cells exposed to oxygen (Nur Alam et al., 2013). The procedure of SOD activity measurement is typically carried out using commercial kit (Cayman, MI, USA) which use a tetrazolium salt for the detection of superoxide radicals generated by xanthine oxidase and hypoxanthine. One unit of SOD is defined as the amount of SOD enzyme needed to produce $50 \%$ dismutation of superoxide radicals (Erujawa et al., 2010). This assay 
measures all SOD types, namely Manganese (Mn), Copper/Zinc $(\mathrm{Cu} / \mathrm{Zn})$, and Iron $(\mathrm{Fe})$ SODs.

The levels of glutathione (GSH), glutathione reductase (GR), glutathione peroxidases (GPO), and glutathione S-transferase (GST) are frequently used as in vivo antioxidant measures. GSH, an intra-cellular reductant involved in oxidation-reduction processes resulting in the formation of glutathione disulfide (GSSG), has been known to play an important role in metabolism, catalysis, and transport. GSH can protect cells against toxic compounds including free radicals and peroxides (Sapakal et al., 2008). The GSH deficiencies can lead to the formation of certain diseases, therefore, any compounds capable of increasing GSH levels are considered as antioxidant (Nur Alam et al., 2013). In addition, GR is an enzyme catalyzing the reduction of GSSG into GSH, a molecule playing a critical role in oxidative stress resistance and the reducing environment maintenance of the cell. GR activity is assayed using the substrate of oxidized glutathione (GSSG). Briefly, $1 \mathrm{~mL}$ of GSSG solution $(2.728 \mathrm{mM}$ and $40 \mu \mathrm{L}$ of pancreatic homogenate) was incubated in the water bath at $37^{\circ} \mathrm{C}$ for 5 mins. The reaction is initiated by the addition of 200 $\mu \mathrm{L}$ of $1.054 \mathrm{mM}$ NADPH solution and the decrease of absorbance is measured at $340 \mathrm{~nm}$ using the spectrophotometer and recorded every $30 \mathrm{~s}$ during the period of 5 mins. The GR activity is expressed as unit per mg protein based on the molar extinction coefficient of $6.22 \times 10^{3} \mathrm{Lmol}^{-1} \mathrm{~cm}^{-1}$. One unit of GR is defined as the amount of enzyme that catalyzes the oxidation of 1 nmol of NADPH per min (Moniruzzaman et al., 2012).

Glutathione peroxidase (GPO), a seleno-enzyme, in which one-third of the enzyme is present in the mitochondria and the remaining in the cytosol. GPO catalyzes the reaction of hydroperoxides with GSH to GSSG and the reduction product of hydroperoxide. The measurement of GPO is particularly important to patients who are under oxidative stress because the low activity of GPO is one of the early consequences of the imbalance between prooxidant and antioxidant (Nur Alam et al., 2013). The activity of GPO is based on the principle of a coupled reaction with glutathione reductase (GR). The oxidized glutathione, GSSG, is formed after the reduction of hydroperoxide by GPO. In the presence of NADPH, GSSH is recycled to its reduced state by GR. The decrease of absorbance value of oxidized NADPH was measured spectroscopically at 340 $\mathrm{nm}$. GPO (one unit) is defined as the amount of enzyme capable of catalyzing the oxidation of $1 \mathrm{nmol}$ of NADPH per min at $25^{\circ} \mathrm{C}$ (Erejuwa et al., 2010).

Glutathione S-transferases (GSTs) are enzymes involved in detoxifying harmful electrophilic endogenous and exogenous compounds. These enzymes are involved during the conjugation of glutathione in phase two metabolism. There are some GST classes (with class members of) namely, alpha (GSTA1, GSTA2, GSTA3, GSTA4, GSTA5), kappa (GSTK1), mu (GSTM1, GSTM1L, GSTM2, GSTM3, GSTM4, GSTM5), omega (GSTO1, GSTO2), pi (GSTP1), theta (GSTT1, GSTT2, GSTT4), zeta (GSTZ1), and microsomal (MGST1, MGST2, MGST3) (Commandeur al., 1995; Sudibyo, 2000; Nur Alam, 2013). Each class of GSTs has specific substrates (Sudibyo, 2000). The activities of GST are typically determined based on the conjugation of GSH to 1-chloro-2,4-dinitrobenzene (CDNB) as a substrate as reported by Habig et al. (1974, based on. Briefly, $2 \mathrm{~mL}$ of potassium phosphate buffer $0.3 \mathrm{M}$ (pH 6.35), $75 \mu \mathrm{L}$ of CDNB solution $30 \mathrm{mM}, 725$ $\mu \mathrm{L}$ of distilled water and $0.1 \mathrm{~mL}$ of pancreatic homogenate are pipetted into a test tube, vortexed and incubated at $37^{\circ} \mathrm{C}$ for 10 mins. After that, the reaction is initiated by the addition of $100 \mu \mathrm{L}$ of reduced $30 \mathrm{mM}$ GSH solution and the decrease of absorbance was measured using spectrophotometer at $340 \mathrm{~nm}$ every $30 \mathrm{~s}$ for the period of $4 \mathrm{~min}$. GST activity is calculated as unit per mg protein based on a molar extinction coefficient of $9.6 \times 10^{3} \mathrm{Lmol}^{-1} \mathrm{~cm}^{-1}$. GST (one unit) was defined as the amount of enzyme catalyzing the conjugation of $1 \mathrm{nmol}$ of GSH-CDNB per min.

Lipid peroxidation (LPE) is an autocatalytic process as a consequence of cell death. This process may cause peroxidative tissue damage in inflammation, cancer and toxicity of xenobiotics and aging. One of lipid peroxidation products during the peroxidation process is malondialdehyde (MDA), a product of free oxygen radicals. MDA is a common indicator of lipid peroxidation (Nur Alam et al., 2013). LPE can be determined based on the procedure by Ohkawa (1979). Initially, the tissues are homogenized in $0.1 \mathrm{M}$ buffer (pH 7.4) to obtain MDA: $0.2 \mathrm{~mL}$ tissue homogenate is added with $0.2 \mathrm{~mL}$ of sodium dodecyl sulfate (SDS) $8.1 \%, 1.5 \mathrm{~mL}$ of acetic acid $20 \%$ and $1.5 \mathrm{~mL}$ of thiobarbituric acid $8 \%$. The mixture is then heated at $95^{\circ} \mathrm{C}$ for 60 mins in the water bath. After incubation, the mixture is cooled at ambient temperature and added with butanol: pyridine $(15: 1 \mathrm{v} / \mathrm{v})$. The mixture is vortexed for 2 mins thoroughly, centrifuged at $3000 \mathrm{rpm}$ for $10 \mathrm{mins}$, and the upper organic layer is measured spectrophotometrically at $532 \mathrm{~nm}$ against a blank. The levels of LPE are expressed as $n$ moles of thiobarbituric acid reactive substances (TBARS)/mg protein using molar extinction coefficient of $1.56 \times 10^{5} \mathrm{MLcm}^{-1}$. 


\section{In vivo antioxidant activities of Curcuma longa}

The rhizome of $C$. longa is probably the most commonly used of Curcuma species in the herbal formulation. The antioxidant effects of $C$. longa are ascribed to the presence of curcuminoids, diarylheptanoid compounds of curcumin, demethoxycurcumin, and bisdemethoxycurcumin, which are considered the main active components in $C$. longa, although their bioavailability can be classified as poor due to low absorption, rapid metabolism and systemic elimination (Ireson et al., 2001; Anand et al., 2007).

The antioxidant activity of $C$. longa in vivo has been investigated by Dall'Acqua et al. (2016) using a metabolomic approach based on NMR and LC-MS/MS data. The results showed that some urinary levels namely $m$-tyrosine, allantoin, nitrotyrosine and 8-hydroxy-2'deoxyguanosine decreased in the rats treated the group with orally administered $C$. longa for 33 days thus supporting the antioxidant effect in vivo of Curcuma extract. Zafir and Banu (2007) also investigated the efficacy of $C$. longa as antioxidant in vivo using Swiss Albino rats subjected to restraint stress. Rats were exposed to stress for $4 \mathrm{hrs}$ during the light phase of the cycle and given with aqueous turmeric extract $(50 \mathrm{mg} / \mathrm{kg})$ orally. The results showed that administration of $C$. longa extract on stressed animals for 21 days prevented restraint stress-induced oxidative damage, as indicated by significant enhancement of superoxide oxidoreductase, glutathione S-transferase, glutathione-NADP+oxidoreductase and GSH, which were severely depleted by restraint stress in control rats.

The study by Baxla et al. (2014) revealed that Wistar albino rats had a significant increase in enzymes of aspartate aminotransferase (AST), alkaline phosphatase (ALP), alanine aminotransferase (ALT), and lipid peroxidation (LPO), decreased in superoxide dismutase (SOD), reduced glutathione (GSH) and increase in the accumulation of lead in liver. In addition, the treatment of C. longa at dose $500 \mathrm{mg} / \mathrm{kg} \mathrm{BW}$ decreased the levels of ALP significantly $(\mathrm{p}<0.01)$, ALT, AST, and LPO levels $(p<0.05)$ as well as increased the levels of GSH compared to group only treated with lead acetate. However, there were no significant differences $(\mathrm{p}>0.05)$ in SOD and lead concentration levels in the liver when compared with the group only treated with lead acetate. From this result, it can be concluded that $C$. longa can decrease liver enzymes and increase antioxidant content. Curcumin, the main active component present in $C$. longa, in the form of nano also revealed to increase reduced glutathione levels and decreased reactive oxygen species and thiobarbituric acid reactive substances levels in rats treated with lead acetate (Flora et al., 2013).

Salama et al. (2013) also investigated the protective effects of ethanolic extract of $C$. longa (EECL) on rats treated with thioacetamide as a hepatotoxin. The oxidative stress was evaluated by measuring the levels of malondialdehyde (MDA), urinary 8-hydroxyguanosine (8-OH-dG) and nitrotyrosine levels, while the protective activities of EECL were evaluated through antioxidant enzymes. The results showed that EECL decreased MDA, nitrotyrosine, and urinary $8-\mathrm{OH}-\mathrm{dG}$ as well as increased antioxidant enzymes of catalase and superoxide dismutase statistically significant $(\mathrm{P}<0.05)$. EECL also revealed to have protective effects in Male Sprague-Dawley rats treated with carbon tetrachloride $\left(\mathrm{CCl}_{4}\right)$ as hepatotoxin. The levels of AST and ALT in the serum and hepatic malondialdehyde had decreased significantly in rats group treated with EECL compared to $\mathrm{CCl}_{4}$-treated group. While, the levels of antioxidant enzymes of SOD, catalase, and glutathione peroxidase activities, as well as glutathione content, increased significantly in EECL group compared to $\mathrm{CCl}_{4}$-treated group. The levels of detoxifying enzymes of glutathione S-transferase (GST) were also found to have increased significantly in EECL group compared to $\mathrm{CCl}_{4}$-treated group. These findings indicated that EECL has protective effects against $\mathrm{CCl}_{4}$-induced hepatotoxicity in rats via antioxidant activities and phase II detoxifying enzymes (Lee et al., 2010). EECL has also been reported to exhibit protective effects in liver injury due to the treatment of $\mathrm{CCL}_{4}$ through increasing levels of antioxidants enzymes of SOD, glutathione peroxidase activity, and glutathione content in the $\mathrm{CCl}_{4}$-treated group $(\mathrm{p}<0.05)$, leading to a reduced lipid peroxidase level (Lee et al., 2017). C. longa extract at the concentration of $0.5 \%$ given to Sprague Dawley rats also revealed the antioxidant activity in vivo. The oral treatment of $C$. longa extract could decrease the levels of MDA, serum urea and creatinine and increased the levels of GSH, SOD and total protein (Morsy et al., 2008).

The antioxidant properties of fermented C. longa (FCL) have been investigated in rats treated with hepatotoxin of $\mathrm{CCl}_{4}$ which induced oxidative stress. FCL at $300 \mathrm{mg} / \mathrm{kg}$ BW orally administered in rats could prevent the elevated levels of serum aspartate aminotransferase (AST), alanine aminotransferase (ALT), alkaline phosphatase (ALP) and lactate dehydrogenase (LDH) caused by $\mathrm{CCl}_{4^{-}}$induced hepatotoxicity. In addition, FCL enhanced the antioxidant capacities with higher activities of catalase, glutathione-S-transferase, glutathione reductase, and glutathione peroxidase, and level of reduced GSH. These findings suggested that FCL could be a developed as an 
alternative protective agent against various diseases induced by oxidative stress through elevating antioxidative and decreasing lipid peroxidation (Kim et al., 2014).

\section{In vivo antioxidant activities of Curcuma xanthorrhiza}

The main components of $C$. xanthorrhiza are starch (48.18-59.64\%), volatile oils (3-12\%) such as phellandrene, camphor, tumoral, cineol, borneol, and xanthorrhizol (1.48-1.63\%), sesquiterpenes $\quad(\beta-$ curcumene, ar-curcumene, bisabolane, lactone germacone), flavonoids (catechin, epicatechin, quercetin, myricetin, kaempferol, apigenin, luteolin, naringenin), and also curcuminoids (Ramdani et al., 2016). Devaraj et al. (2014) have investigated the antioxidant activities of C. xanthorrhiza in vivo on Male Sprague Dawley rats $(150-200 \mathrm{~g})$ treated with carbon tetrachloride $\left(\mathrm{CCl}_{4}\right)$ as hepatotoxin. The hexane fraction of $C$. xanthorrhiza could serve as hepato-protector via antioxidant activities. Rats treated with $\mathrm{CCl}_{4}$ indicated the decreased levels of glutathione peroxidase (GPx), superoxide dismutase (SOD), glutathione reductase (GR), catalase (CAT), and total protein (TP) and the increased level of malondialdehyde (MDA) levels in the liver compared to rats in control group. But, the treatment of hexane fractions of C. xanthorrhiza at doses of $250 \mathrm{mg} / \mathrm{kg}$ and $500 \mathrm{mg} / \mathrm{kg}$ returned the antioxidant enzymes as in control rats. This indicated that $C$. xanthorrhiza could act as antioxidant and may prevent the peroxidation of lipids induced by $\mathrm{CCl}_{4}$. C. xanthorrhiza also revealed antioxidant activities on rats treated with single dose of $\beta$ -D-galactosamine $(288 \mathrm{mg} / \mathrm{kg})$ intra-peritoneal (Lin et al., 1996) and those treated for $\mathrm{CCl}_{4}$ (Lin et al., 1995). Devaraj et al. (2010) also proved that C. xanthorrhiza ethanolic extract $(500 \mathrm{mg} / \mathrm{kg})$ could increased antioxidant enzymes in acute hepatic diseases.

Alkiyumi (2013) has investigated the hepatoprotective activities of $C$. xanthorrhiza through evaluation of levels of antioxidant enzymes (SOD and CAT) and level of MDA. C. xanthorrhiza extract was subjected to fractionation. Fraction 5 of this extract revealed the highest levels of SOD and CAT on rats treated with thioacetamide. The active compounds identified using LC-MS/MS for these activities is xanthorrhizol. The ethanolic extract of $C$. xanthorrhiza rhizome (EECR) on the levels of GPx and MDA in the brains of trimethyltin (TMT) induced dementia model rats was evaluated by Yuliani et al. (2017). There is a significant difference between normal group rats and treated group rats $(\mathrm{p}<0.05)$.
Curcuma species, especially $C$. longa and $C$. xanthorrhiza contained some phenolics compounds (curcuminoids) which played important roles in antioxidant activities. Using animal models, both Curcuma revealed high antioxidant activities as indicated by increasing levels of antioxidant enzymes of catalase, glutathione reductase, superoxide dismutase, glutathione peroxidase, and glutathione S-transferase and decreasing lipid peroxidation levels. C. longa and C. xanthorrhiza could be used as a preventive agent to any diseases caused by excessive radicals.

\section{Acknowledgement}

The authors acknowledged the Ministry of Research and Higher Education, the Republic of Indonesia for financial support during preparing this review article through scheme World Class Research 2019 with contract number of 1973/UN1.DITLIT/DIT-LIT/ $\mathrm{LT} / 2019$.

\section{References}

Alkiyumi, S.S.S. (2013). A study of hepatoprotective effects of Curcuma xanthorrhiza and Ipomoea aquatica on thioacetamide-induced liver cirrhosis in rats. Malaysia: Universiti Malaya, MSc. Thesis.

Anand, P., Kunnumakkara, A.B., Newman, R.A. and Aggarwal, B.B. (2007). Bioavailability of curcumin: problems and promises. Molecular Pharmaceutics, 4 (6), 807-818. https://doi.org/10.1021/mp700113r

Baxla, S.L., Gora, R.H., Kerketta, P., Kumar, N., Roy, B.K. and Patra, P.H. (2013) Hepatoprotective effect of Curcuma longa against lead induced toxicity in Wistar rats.Veterinary World, 6(9), 664-667. https:// doi.org/10.14202/vetworld.2013.664-667

Commandeur, J.M.N., Stijntjes, G. and Vermeulen, N.P.E. (1995). Enzymes and transport systems involved in the formation and disposition of glutathione S-conjugates. Pharmacology Review, 47 (2), 271-330.

Dall'Acqua, S., Stocchero, M., Boschiero, I., Schiavon, M., Golob, S., Uddin, J., Voinovich, D., Mammi, S. and Schievano, E. (2016). New findings on the in vivo antioxidant activity of Curcuma longa extract by an integrated ${ }^{1} \mathrm{H}-\mathrm{NMR}$ and HPLC-MS metabolomic approach. Fitoterapia, 109, 125-31. https://doi.org/10.1016/j.fitote.2015.12.013

Dragland, S., Senoo, H., Wake, K., Holte, K. and Blomhoff, R. (2003). Several culinary and medicinal herbs are important sources of dietary antioxidants. The Journal of Nutrition, 133(5),12861290. https://doi.org/10.1093/jn/133.5.1286

Devaraj, S., Ismail, S., Ramanathan, S. and Yam, M.F.

\section{Conclusion}


(2014). Investigation of antioxidant and hepatoprotective activity of standardized Curcuma xanthorrhiza rhizome in carbon tetrachlorideinduced hepatic damaged rats. The Scientific World Journal, 2014, $\quad 1-8 . \quad$ https:// doi.org/10.1155/2014/353128

Devaraj, S., Ismail, S., Ramanathan, S., Marimuthu, S. and Fei, Y.M. (2010). Evaluation of the hepatoprotective activity of standardized ethanolic extract of Curcuma xanthorrhiza Roxb. Journal of Medicinal Plants Research, 4(23), 2512-2517. https://doi.org/10.5897/JMPR10.453

Flora, G., Gupta, D. and Tiwari, A. (2013). Preventive efficacy of bulk and nanocurcumin against leadinduced oxidative stress in mice. Biological Trace Element Research, 152(1), 31-40. https:// doi.org/10.1007/s12011-012-9586-3

Harwort, J.E. (2003). Natural antioxidants review. Proceedings of the 56th American Meat Science Association Reciprocal Meat Conference, p. 95-98. Colombia, Missouri: AMSA.

Hosseini, A. and Hosseinzadeh, H. (2018). Antidotal or protective effects of Curcuma longa (turmeric) and its active ingredient, curcumin, against natural and chemical toxicities: A review. Biomedicine and Pharmacotherapy, 99, 411-421. https:// doi.org/10.1016/j.biopha.2018.01.072

Ireson, C., Orr, S., Jones, D.J.L., Verschoyle, R., Lim, C., Luo, J., Howells, L., Plummer, S., Jukes, R., Williams, M., Steward, W.P. and Gescher, A. (2001). Characterization of metabolites of the chemopreventive agent curcumin in human and rat hepatocytes and in the rat in vivo, and evaluation of their ability to inhibit phorbol ester-induced prostaglandin E2 production. Cancer Research, 61 (3), 1058-1064.

Jiang, T.A. (2019). Health Benefits of Culinary Herbs and Spices. Journal of AOAC International, 102, 395 -411. https://doi.org/10.5740/jaoacint.18-0418

Kim, Y., You, Y., Yoon, H.G., Lee, Y.H., Kim, K., Lee, J., Kim, M.S., Kim, J.C. and Jun, W. (2014). Hepatoprotective effects of fermented Curcuma longa L. on carbon tetrachloride-induced oxidative stress in rats. Food Chemistry, 151, 148-153. https:// doi.org/10.1016/j.foodchem.2013.11.058

Kumar, S., Sharma, S. and Vasudeva, N. (2017). Review on antioxidants and evaluation procedures. Chinese Journal of Integrative Medicine, 2017, 112. https://doi.org/10.1007/s11655-017-2414-z

Lee, H.S., Li, L., Kim, H.K., Bilehal, D., Li, W., Lee, D.S. and Kim, Y.H. (2010). The protective effects of Curcuma longa Linn. Extract on carbon tetrachloride -induced hepatotoxicity in rats via upregulation of Nrf2. Journal of Microbiology and Biotechnology, 20(9),1331-1338. https://doi.org/10.4014/ jmb.1002.03010

Lee, G.H., Lee, H.Y., Choi, M.K., Chung, H.W., Kim, S.W. and Chae, H.J. (2017). Protective effect of Curcuma longa $\mathrm{L}$. extract on $\mathrm{CCl}_{4}$-induced acute hepatic stress. BMC Research Notes, 10, 77. https:// doi.org/10.1186/s13104-017-2409-z

Lin, S.-C., Teng, C.-W., Lin, C.-C., Lin, Y.-H. and Supriyatna, S. (1996). Protective and therapeutic effect of the Indonesian medicinal herb Curcuma xanthorrhiza on $\alpha$-d galactosamine-induced liver damage. Phytotherapy Research, 10(2), 131-135. https://doi.org/10.1002/(SICI)1099-1573(199603) 10:2<131::AID-PTR786>3.0.CO;2-0

Lin, S.C., Lin, C.C., Lin, Y.H., Supriyatna, S. and Teng, C.W. (1995). Protective and therapeutic effects of Curcuma xanthorrhiza on hepatotoxin-induced liver damage. The American Journal of Chinese Medicine, 23, 243-254. https://doi.org/10.1142/ S0192415X95000298

Lubrano, V. and Balzan, S. (2015). Enzymatic antioxidant system in vascular inflammation and coronary artery disease. World Journal of Experimental Medicine, 5(4), 218-24. https:// doi.org/10.5493/wjem.v5.i4.218

Moniruzzaman, M., Khalil, M.I., Sulaiman, S.A. and Gan, S.H. (2012). Advances in the analytical methods for determining the antioxidant properties of honey: A Review. African Journal of Traditional, Complementary, and Alternative Medicines, 9(1), 36 -42. https://doi.org/10.4314/ajtcam.v9i1.5

Morsy, G.M., El Sayed, H.H., Hanna, E.I. and Abdel Rahman, M.K. (2008). Turmeric may protect cells from oxidative stress by acrylamide in-vivo. The Egyptian Journal of Forensic Sciences and Applied Toxicology, 4, 123-129.

Nugroho, A., Rohman, A., Lukitaningsih, E., Rakhmawati, N. and Sudjadi, S. (2015). Analysis of curcumin in ethanolic extract of Curcuma longa Linn. and Curcuma xanthorrhiza Roxb. using high performance liquid chromatography with UVdetection. Research Journal of Phytochemistry, 9(4), 188-194. https://doi.org/10.3923/ rjphyto.2015.188.194

Nur Alam, M., Bristi, N.J. and Rafiquzzam, M. (2013). Review on in vivo and in vitro methods evaluation of antioxidant activity. Saudi Pharmaceutical Journal, 21(2), 143-152. https://doi.org/10.1016/ j.jsps.2012.05.002

Ohkawa, H., Onishi, N. and Yagi K. (1979). Assay for 
lipid peroxidation in animal tissue by thiobarbituric acid reaction. Analytical Biochemistry, 95, 351-358. https://doi.org/10.1016/0003-2697(79)90738-3

Opara E.I. and Chohan, M. (2014). Culinary herbs and spices: their bioactive properties, the contribution of polyphenols and the challenges in deducing their true health benefits. International Journal of Molecular Sciences, 15(10), 19183-19202. https:// doi.org/10.3390/ijms 151019183

Pandey, K.B. and Rizvi, S.I. (2009). Plant polyphenols as dietary antioxidants in human health and disease. Oxidative Medicine and Cellular Longevity, 2(5), 270-278. https://doi.org/10.4161/ oxim.2.5.9498

Podsedek, A. (2007). Natural antioxidants and antioxidant capacity of Brassica vegetables: A review. LWT-Food Science and Technology, 40(1), 1 -11. https://doi.org/10.1016/j.lwt.2005.07.023

Rajkumari, S. and Sanatombi, K. (2017). Nutritional value, phytochemical composition, and biological activities of edible Curcuma species: A review. International Journal of Food Properties, 20(Suppl. 3), S2668-S2687. doi.org/10.1080/10942912.2017.1387556

Ramdani, E.D., Marlupi, U.D., Sinambela, J. and Tjandrawinata, R.R. (2016). A new method of xanthorrhizol isolation from the rhizome extract of Curcuma xanthorrhiza. Scholars Academic Journal of Bioscience, 4(9), 732-737.

Salama, S.M., Abdulla, M.A., AlRashdi, A.S., Ismail, S., Alkiyumi, S.S. and Golbabapour, S. (2013). Hepatoprotective effect of ethanolic extract of Curcuma longa on thioacetamide induced liver cirrhosis in rats. BMC Complementary and Alternative Medicine, 13, 1-17. https:// doi.org/10.1186/1472-6882-13-56

Sapakal, V.D., Shikalgar T.S., Ghadge, R.V., Adnaik, R.S., Naikwade, N.S. and Magdum, C.S. (2008). In vivo screening of antioxidant profile: a review. Journal of Herbal Medicine and Toxicology, 2, 1-8. https://doi.org/10.4103/0973-8258.41175

Serafini, M. and Peluso, I. (2016). Functional foods for health: The interrelated antioxidant and antiinflammatory role of fruits, vegetables, herbs, spices and cocoa in humans. Current Pharmaceutical Design, 22(44), 6701-6715. https:// doi.org/10.2174/1381612823666161123094235

Sudibyo, M. (2000). Inhibition of Glutathione STransferase by Curcumin and its Derivatives, Molecular Mechanism and Qualitative StructureActivity Relationship. Yogyakarta: Universitas Gadjah Mada, PhD Dissertation.
Tapsell L.C., Hemphill I., Cobiac L., Sullivan D.R., Fenech M., Patch C.S., Roodenrys S., Keogh J.B., Clifton P.M., Williams P.G., Fazio, V.A., Inge, K.E. and Patch, C.S. (2006). Health benefits of herbs and spices: The past, the present, the future. The Medical Journal of Australia, 185, S1-S24.

Weydert, C.J. and Cullen, J.J. (2010). Measurement of superoxide dismutase, catalase, and glutathione peroxidase in cultured cells and tissue. Nature Protocols, 5, 51-66. https://doi.org/10.1038/ nprot.2009.197

Xia, Q., Zhao, K.Z., Huang, Z.G., Zhang, P., Dong, T.X.X., Li, S.P. and Tsim, K.W.K. (2005). Molecular Genetics and Chemical Assessment of Rhizome Curcumae in China. Journal of Agriculture and Food Chemistry, 53(15), 6019-6026. https:// doi.org/10.1021/jf0508495

Yuliani, S., Prasetya, D.Y. and Bachri, M.S. (2017). Effect of Temulawak (Curcuma xanthorrhiza Roxb.) extract on the MDA levels and GPx activity in the brains of trimethyltin induced dementia model rats. Advanced Science Letters, 23, 12451-12454. https:// doi.org/10.1166/asl.2017.10790

Zafir, A. and Banu, N. (2007). Antioxidant potential of fluoxetine in comparison to Curcuma longa in restraint-stressed rats. European Journal of Pharmacology, 572(1), 23-31. https:// doi.org/10.1016/j.ejphar.2007.05.062 